\title{
Technology-enhanced fiber optic education
}

\author{
Joseph Palais
}

Joseph C. Palais, "Technology-enhanced fiber optic education," Proc. SPIE 3831, Sixth International Conference on Education and Training in Optics and Photonics, (16 June 2000); doi: 10.1117/12.388732

Event: Education and Training in Optics and Photonics (ETOP'99), 1999, Cancun, Mexico 


\title{
Technology-enhanced fiber-optic education
}

\author{
Joseph C. Palais \\ Department of Electrical Engineering \\ Arizona State University \\ Tempe, Arizona 85287-5706
}

\begin{abstract}
Personal computers and the Internet have revolutionized the modern classroom in several ways. Many classes are now taught in technology-enhanced classrooms where computers are available to aid the instructor's presentation. Availability of the Internet further increases the instructor's options by providing convenient access to an abundance of outside material and by providing an effective means of distance delivery. Applications of these technologies to courses in optical fiber communications are described.
\end{abstract}

Keywords: photonics education, fiber optics, Internet

\section{INTRODUCTION}

This discussion on technology enhancement in the classroom is applicable to most areas of engineering education.. However, the author's experience is primarily in teaching optical fiber communications, so that all examples will be drawn from there.

I have presented fiber-optics courses in a number of formats over a period of more than 20 years. Many of my own experiences have paralleled the general trends in engineering education over this period of time. Actually, while summarizing my teaching experiences, I was surprised to find that I had participated in so many different ones. For both university credit courses and for non-credit short courses, I have used conventional classroom lectures and televised lectures. I have also delivered correspondence courses by mail. In addition, although not much feedback is available, I have participated in selflearning by those who have purchased my textbook and have studied fiber optics on their own. The conventional lectures and most of the television instruction were for senior-level and graduate-level credit courses, while the short courses and the correspondence courses were for continuous learning and self improvement at all levels. The descriptions to follow show the gradual increase in the use of technology in the classroom with time.

Although the Internet has not yet been used directly for delivery of my courses, it has played an ever-increasing part in the various course formats I have used.

This paper treats optics education from the perspective of delivery techniques as opposed to one that describes photonics curricula and course content. ${ }^{1}$

\section{CONVENTIONAL LECTURES}

Conventional lecture classes consisted of standard blackboard- and, later, whiteboard-equipped classrooms. In some cases, overhead transparencies were prepared for use as part of the lecture. This tended to speed up the lecture to the point where students could not follow, particularly if taking notes. Handing out printed notes is a solution, but generally the use of transparencies does not effectively enhance the formal classroom experience.

While the overhead projector is a modest technological enhancement for university credit courses, it is excellent for short courses and technical presentations at meetings and conferences.

Although for the most part university-level courses are still presented in the conventional lecture format, many electrical engineering classes are now being taught over television in computer-equipped studios for distance delivery or in computerenhanced classrooms at my home institution, Arizona State University (ASU). This appears to be one direction in which university education is heading. 


\section{TELEVISED LECTURES}

A television distribution delivery system was installed at ASU in the mid-1980s because of demand for course delivery to the many electronics firms in the local Phoenix area. Initially television studios were constructed which could accommodate about 60 students in the studio, while broadcasting to more than twenty-five local companies. Although students in the studio can see the professor, they view the professor's notes on TV monitors distributed around the room. The professor writes on a pad, which is covered by one of the two TV cameras in the studio. At times there were more than 60 on-campus students in the fiber-optics classes. The excess students were served in a second overflow room where the lectures were viewed live on TV monitors.

The off-campus population has varied over the years. It has been as high as 20 students. Telephone access to the lecturer was provided during the broadcast for participants at the local TV sites and in the overflow studio. Generally, the telephone was not used very much by the students. It does not seem to be a successful addition to the course. I believe this is because the telephone is a dial-up system, so that there is a delay in reaching the instructor and also because of the reluctance to ask questions in the television broadcast format. Most off-campus questions arrive during calls to the office and by e-mail.

Subsequent technological enhancements to the TV system were: (1) addition of a computer for use by the instructor, (2) video taping capability, (3) satellite distribution of the class, and (4) access to the Internet by the instructor during the lecture.

\subsection{Computers}

Early in the 1990s, computers were installed in the television studios so that teaching material could be prepared ahead of time, stored on the computer's hard drive, and shown during the lecture period. This technological enhancement encouraged the development of software to demonstrate various optical and fiber-optic behavior. The software was run as part of the lecture presentation.

\subsection{Video taping}

Video taping of classes was a natural addition to the video distribution system. At first taping was limited to the local companies that were receiving the live broadcasts. Many employees found it more convenient to watch the broadcasts at a time of their choosing rather than at the time of transmission, even though they lost the ability to call in questions. This behavior emphasized the customer desires for an "any time" learning opportunity. Of course, by taking the tapes home they also produce an (almost) "any place" opportunity as well. I say "almost" because the tapes can only be viewed at a place where there is access to a VCR and monitor. In essence, we have the beginnings of an individualized, student-designed, course environment. The student chooses the place and the time of the learning experience, rather than the school or the professor. The remote student still had to keep up with the campus mandated homework and exam schedule.

In the early days of the ASU television system, video tapes of the lectures were not provided to on-campus students. This changed a few years ago. Now students can check out tapes from a central video library. The interesting result of this technological enhancement is that a number of on-campus students do not attend the live lectures, but instead view the tapes at what they consider more convenient times. The video tape service was not intended for this purpose. It was intended to serve as an emergency backup for students who missed classes because of unavoidable circumstances. This behavior has been reported for most televised classes and should be investigated to determine why it is so popular. A few students that I interviewed reported that they liked viewing taped lectures because of their ability to replay portions of the lecture as desired and they liked choosing the time and place for viewing the class lectures. The on-campus student's desire to behave as a "virtual" distance learner indicates an enthusiasm for course delivery systems that differ from the conventional in-class format.

Video taping allows mailing copies of taped lectures to students at locations not served by the television distribution network. ASU does this through its College of Extended Education. Although I have not participated in this process, it has been done for several electrical engineering classes. Completed homework and exams are mailed to the University. Arrangements for monitoring exams are done through local schools and libraries. Mailing of tapes seems a bit cumbersome, considering the amount of physical material that must be handled and sent through the mail and the accompanying time delays. The use of 
University personnel time is high for this delivery system. Nonetheless, it does provide the convenience of any time, any place, course delivery desired by some students.

\subsection{Satellites}

When ASU became part of the National Technological University (NTU) system, the fiber-optics classes were offered for satellite distribution. Although the system is designed for live broadcasts, because of the time differences across the country the ASU classes are transmitted by satellite to NTU for distribution later in the day to company sites where students are located. Typically the companies tape the lectures for viewing at a convenient time and place for the student. Now we have a second component added in the convenience category. Satellite delivery brings the lectures close to the student's work environment, giving convenience of place, but not of time. Adding tape provides convenience of time as well, at least within a window of a few days or so. The limit on time occurs because of the requirement to finish certain materials, do and return homework, and be ready for exams, on a schedule coinciding with that of the on-campus students.

\subsection{Internet}

The Internet is becoming such a major player in engineering education that it will be further discussed in a full section of its own (Section 5).

\subsection{Assessment}

Over the many years of operation, the ASU television programs have received very positive student endorsements. I believe the convenience provided to off-campus students is the primary reason for their participation and continued enthusiasm. Reducing (or eliminating) travel time to attend classes is a major contribution of distance delivery systems. Providing variable times for viewing the lectures (by taping) is another component of the convenience factor.

Convenience is a key measure of the viability any educational innovation. The convenience factor must be evaluated for any technology-driven educational innovation. Without this feature, students will not participate. In distance learning systems, the off-campus student behaves more like a customer than does the on-campus student. Once the on-campus student has committed to a given school, that student has only limited input into what courses are offered or the time schedule for those classes. The off-campus graduate engineering student generally is working full-time and has a limited amount of time available for education. Travel distance to a physical classroom is limited also, although this is really tied to the time restriction. The off-campus engineering student now has a choice of educational providers since many institutions provide televised, tape-delivered, and Internet courses. On-campus courses have traditionally been presented under the assumption that students have an unlimited amount of time to devote to their studies. Although it should not be so, student convenience is low on the list of priorities when designing traditional on-campus programs. This cannot be the case for distance-delivered programs, because of the educational choices available.

\section{TECHNICAL ADVANCES}

Many new technological developments have made possible (and driven) innovations in educational content and delivery over the last 20 years. A few of these advancements are: television, personal computers, digital cameras, transmission by optical fibers, satellites, and microwave systems, VCRs, video compression, video streaming, FAX, e-mail, and the Internet. These, and others, have contributed to the possibilities for new approaches to educational presentations

\section{FIBER OPTICS ON THE INTERNET}

The Internet plays (at least) two distinct rolls in the technologically-enhanced classroom: (1) it provides a medium for course delivery, and (2) it provides access to an abundance of material for use to complement classroom lectures. Course delivery over the Internet is a major educational tool with enormous ramifications for existing educational institutions. For one, it provides a method for course delivery from a variety of educational providers into the geographic region once served only by a local institution. The effect of this type of competition has yet to be evaluated. However, this paper will emphasize the second roll of the Internet, as it is important and it is where my own past experience lies. 
Two types of computer-equipped classrooms are now in common use. In one case, networked computers are available to the students attending the lectures so they can work examples, search out individual information, and view examples produced by the lecturer. In the second case, (the one I most often use and am reporting on) only the instructor has computer access during the lectures, but the students can view the computer monitor and can recreate the computerized material on their own after the scheduled class period. In most classes, computer presentations are shown using video projectors. In my televised classes, the computer output is directly switched to the television monitors, permitting all students to view the programs during the lectures. The television operator switches between the classroom view and the computer view as appropriate during the class meeting. The picture quality over the television monitors is brighter than over most video projectors. Initially, the computers were stand-alone devices allowing only preloaded software to be run. Later, Internet access was made available. All students have access to the Internet on their own or on University provided computers, giving them access to the programs run during the lectures.

A variety of material for the fiber optics course is available on my Internet web pages." There is the course syllabus, including the course description, the lecture and reading schedule, and exam dates. Homework assignments are available as well as password-protected homework solutions.

The fiber optics course is taught with a laboratory, so the laboratory manual is also on the web page. A digital camera was used to photograph the laboratory setups and the pictures placed on the web page to add to the written descriptions of the required experiments. This provides more information for the students than does the conventional laboratory manual. In addition, modifications of the laboratory experiments can be easily documented on the web page. Future improvements include producing videos of the experiments for the web to further increase the utility of the laboratory manual. Hard-copy versions of the course syllabus and laboratory manual are no longer produced.

The Internet contains an abundance of fiber-optic materials. All major manufacturers provide information on their products on the web. Some also provide tutorials. This information is called up at appropriate times during the lectures as practical illustrations of available fiber components and systems and to teach the students how to access this rich resource. Students appreciate the insertion of practical, real-life, components to augment the theoretical material contained in the usual lectures. In addition to the class material already described, specially designed fiber-optic demonstrations are placed on the web as described in the next section.

\section{SIMULATIONS}

Much optical and electrical phenomena involves motion: the motion of waves, the movement of photons, electrons, and holes, and the transport of information, for examples. Yet, in most lectures the best that can be done is to indicate the fact that motion occurs or sketch a few positions of the changing phenomenon as time progresses. Movies and video tapes of optical and electrical phenomena have been available for years, but the equipment for viewing them is too cumbersome to be widely used in many lecture situations. However, computer simulated motion is attractive for presentations in the computerequipped classroom. When, in addition, the simulations can be stored on the Internet and called up for viewing whenever desired, the combination becomes very attractive for lecture enhancement. The simulations that I have used fall into two classifications: demonstration of phenomena or component usage and fast calculation of optical characteristics. The demonstrations to be described can be viewed on my fiber-optic web pages. ${ }^{*}$

\subsection{Simulations of phenomena}

The following are a few of the many simulations subjects developed demonstrating phenomena important to fiber optics: wave travel, scattering, propagation in a GRIN fiber, LED operation, stimulated emission and optical amplification, wavelength-division multiplexing, and pulse spreading in a fiber. A few of these will be described. I have not included any drawings in this paper as they do an injustice to the dynamic simulations as they appear when the programs are run.

In the wave simulation, the wave travels with adjustable amplitude, frequency, wavelength, speed, and attenuation. The scattering simulation shows photons scattered in arbitrary directions as they travel through the fiber. The phenomenon of

* http://www.eas.asu.edu/ p palais 
decreased scattering with increasing wavelength for Raleigh scattering is demonstrated. The pulse spreading program shows distinct pulses broadening, and eventually overlapping, as they travel along the fiber. This demonstrates intersymbol interference. The LED simulation shows the energy-level diagram of a pn junction. As the bias voltage is increased, the potential barrier lowers, electrons and holes are injected into the depletion region, and they combine with the consequent emission of photons. As is appropriate, different colored photons are emitted when the bandgap energy is changed.

\subsection{Computer calculations}

The speed of the computer permits fast calculation as parameters in a problem are varied. A few examples we have prepared calculate and plot reflectance versus incident angle at a plane dielectric boundary with refractive index as a variable, calculate and plot the mode chart for a dielectric slab waveguide, and calculate and sketch the effects of material dispersion on a propagating pulse. These and other programs are inserted into the lectures at appropriate times throughout the semester. The speed at which the programs load and run are important. In a typical 50 minute class, there is no time to waste while waiting for programs to load, start up, and run.

\subsection{Other web-based information}

An abundance of fiber-optic applicable information is available on the Internet. Various industrial pages are called up during the lectures. One frequently accessed web page describes commercial fibers. ${ }^{* *}$ Commercial web pages show products, product specifications, and news. Some web sites include useful short tutorials as well.

\subsection{Assessment}

A student assessment is obtained at the end of most course presentations. I have found it interesting that the most often mentioned aspects of the fiber course presentation are the computer simulations. The remarks are positive and indicate several things. Visually stimulating computer images come more quickly to mind than do theoretically important portions of the lecture when a student is recalling the semester's events. The computer demonstrations make more of an impression than do the lecture portions of the course. In addition, students seem to enjoy the computer and animated presentations. Maybe this is just a manifestation of the fact that present students have been brought up in an environment where visual stimulation has been pervasive. They are most comfortable and accepting of educational techniques which complement this background.

Although I have not taught a course delivered over the Internet, several have done so at ASU by recording their lectures in the television studios in front of the on-campus students. The behavior mentioned in Section 3.2, where on-campus students do not attend lectures but instead view video tapes of the lecture was repeated. In this case, the on-campus students simply watched the lecture on the Internet at a time and place they found convenient. The Internet classes are even more convenient for on-campus students than the video-taped classes, as students do not have to physically pick up the recorded video tapes.

\section{SHORT COURSES}

I have presented numerous fiber optic short courses over the past 20 years. These have ranged in length from four hours to three days. They began as lecture presentations using overhead transparencies. Computer simulations were added and, later, simulations from the Internet were included just as in the televised lectures described previously. It is a little bit cumbersome to switch between transparencies and computer simulations. The overhead projector must be turned off and the video projector turned on. Unfortunately, the ambient lighting must usually be turned down to view the more dimly projected computer images. Although the problem just described is not insurmountable, a smoother transition between the computer and non-computer materials would be more desirable. The television classroom used for the university credit courses provides a smoother transition.

I have presented a one-day televised fiber-optics short course distributed over satellite for live viewing several times. Instead of the transparencies, all notes were contained on hard copies and displayed on the TV monitors. The computer simulations

** http://www.corningfiber.com 
were easily accessed as in the televised credit classes. This procedure works very well. In addition to the live broadcast, the program was videotaped for later distribution to interested individuals and groups.

An alternative procedure for both the televised classes and the short courses would be to have all the materials on the computer. Lecture material could be on PowerPoint slides to be compatible with the simulations. Switching between lecture material and simulations becomes seamless. Equipment reliability now becomes an issue, particularly when traveling and presenting the course in a new environment. At the present time, lecturers traveling with notebook computers and PowerPoint presentations continue to bring along transparencies as backups.

\section{TEXTBOOK}

The ultimate educational experience is one that provides the required information at any time and at any place and can be studied on a schedule determined by the student. Although certainly not a high tech solution, a textbook fulfills this requirement. My fiber communications textbook ${ }^{2}$ has gone through four editions since its inception in 1984. It is available in an international edition and has been translated into Japanese and Korean. Although the book has been mostly used in college courses, I believe many purchasers have utilized the book for self study. It is difficult to assess this application of the book, but self learning is a valid educational process. It is worth considering giving college credit for self-taught courses upon appropriate examination and evaluation. With distance learning becoming so popular, this concept seems more acceptable than it might have been a few years ago. Many degrees are already granted to students who have never been anywhere near the degree-granting institution. Testing could be done electronically, adding a high-tech component to the process. The "virtual campus" now under construction by many institutions might well include self-taught course credits.

\section{CORREPONDENCE COURSE}

One of the oldest educational distance-delivery systems is the correspondence course. It shares many of the same characteristics as an Internet-delivered course. A correspondence course certainly satisfies the "any time" and "any place" condition. I have directed a non-credit, fiber-optics correspondence course for many years. Reading assignments are made, homework problems are solved, and class papers are submitted, all through the mail. The course is not for credit and the various sections can be done on the schedule desired by the student. Unfortunately, even though the students pay for the course, only a few have ever completed the entire program. With no grades given and recorded, and no set time limits, the motivation to make progress and excel is not present. I strongly believe that (with or without computers and the Internet) courses will have limited success without the driving factor of schedules and grades. Only those students possessing the greatest drive will set aside the time necessary to complete the assignments in a timely manner without the motivation provided by a schedule and a grading scheme.

\section{CONCLUSION}

Technology is changing the way that engineering education is being presented. The personal computer and the Internet have inspired a wide range of innovations to the standard teaching process. The major attractions are those related to distance learning and to visual presentations (which include both still pictures and animated ones). Distance learning provides great student convenience. Pictures can illustrate phenomena in a unique way, captivating student interest and, hopefully, increasing their understanding.

Compared to the standard classroom lecture, the hardware requirements present an added financial feature and the preparation times present an added time commitment. Interestingly, some administrators look upon distance learning as a way to lower educational costs because of the reduced need to construct physical classrooms. It is not yet clear that a cost savings will actually occur. The "virtual classroom" and "virtual university" are intriguing concepts which have begun to change the educational process.

Technology in the educational process is well accepted by the present generation of learners. There is little question that the trend to utilizing more technology in the classroom will continue. There should, however, be evaluations of the effectiveness of the technologically-enhanced classroom in all its various forms. Both costs and learning must be evaluated and compared to conventional educational processes. 


\section{REFERENCES}

1. J. Palais, N. Gallagher and H. Stark, "Photonics Enrichment of the Electrical Engineering Curriculum," IEEE Trans. on Educ., 35, pp. 103-108, 1992.

2. J. Palais, Fiber Optic Communications, Prentice-Hall, $4^{\text {th }}$ ed., Upper Saddle River, NJ, 1998. 